\title{
SEGURANÇA DO PACIENTE EM SALA DE OPERAÇÕES: \\ O ENFERMEIRO E A UNIDADE DE ELETROCIRURGIA
}

\author{
Brigitta Pfeiffer Castellanos *
}

CASTELLANOS, B.P. - Segurança do paciente em sala de operações: o enfermeiro e a unidade de eletrocirurgia. Rev. Esc. Enf. USP,7(2):123$139,1973$.

$A$ unidade de eletrocirurgia é um aparelho eletrônico que tem como objetivo promover a eletrocoagulação e a eletrodissecção. Como qualquer outro equipamento eletrônico, seus beneficios potenciais podem ser anulados, ou seu uso pode levar a desastrosas consequências, caso haja omissão ou desconhecimento com relação ao seu funcionamento, manejo $e$ conservação. $A$ avaliaçāo das circunstâncias que envolvem queimaduras $e$ problemas de interferência no paciente e em outros equipamentos eletrônicos contribui para maior segurança do paciente na sala de operaçōes (S.O.).. São analisadas as possiveis causas de queimaduras e é focalizado o papel do enfermeiro.

\section{INTRODUÇÃO}

Motivadas pela inexistência de literatura atualizada em língua portuguesa sobre $o$ assunto, e estimuladas pelo crescente interesse de profissionais responsáveis por pacientes submetidos à eletrocirurgia e de alunos da disciplina de Enfermagem em Centro Cirúrgico, tentamos, neste trabalho, analisar o tema. Procuramos, dentro de nossas possibilidades, esgotar o assunto, com detalhes que, muitas vezes, apesar de minuciosos, são vitais para o paciente.

\footnotetext{
- Auxiliar de Ensino da disciplina Enfermagem em Centro Cirúrgico.
} 
Tentamos avaliar as circunstâncias que envolvem queimaduras e problemas de interferência, no paciente e em equinamentos eletrônicos. Sabemos que tal avaliação necessita do auxílio de um profissional especializado, mas consideramos responsabilidade do enfermeiro o conhecimento sobre os princípios de funcionamento e a problemática geral envolvida, pois, será ele o responsável pelo uso, manejo e manutenção da unidade de eletrocirurgia, direta ou indiretamente. $O$ que puder ser feito a fim de aumentar a atenção do pessoal da SO para os riscos em potencial significará maior segurança para o paciente. Foi este o nosso objetivo.

A tecnologia eletrônica, apesar de trazer novas possibilidades e facilidades aos hospitais, também criou novos perigos e responsabilidades. Os benefícios potenciais do equipamento eletrônico podem ser anulados e, às vezes, levar a trágicas consequências, caso haja desconhecimento ou omissão em relação ao seu funcionamento, adequado manejo e conservação.

Um dos resultados do desenvolvimento da eletrônica aplicada à instrumentação médica foi a introdução da Unidade de Eletrocirurgia (usualmente conhecida como bisturi elétrico), com o objetivo de promover a eletrodisseç̧ão e a eletrocoagulação de vasos durante o ato cirúrgico.

Analisaremos os princípios do funcionamento da Unidade de Eletrocirurgia com o intuito de compreender não só os seus objetivos, mas também o seu funcionamento e outros fatores que possam interferir na precisão do equipamento ao seu redor. Nossa finalidade é discorrer sobre riscos em potencial no uso do bisturi elétrico e verificar como o enfermeiro de SO pode contribuir para a maior segurança do paciente.

\section{PRINCIPIOS DA ELETROCIRURGIA}

A Unidade de Eletrocirurgia é um aparelho eletrônico que tem a propriedade de transformar a corrente elétrica alternada comum em corrente elétrica de tão alta frequência que, apesar de sua intensidade, não provoca migração de íons no organismo, nem ocasiona excitação farádica nos nervos.

Os aparelhos variam conforme a marca e podem ser de diferentes tamanhos, portáteis ou fixos à parede ou ao teto da SO. 


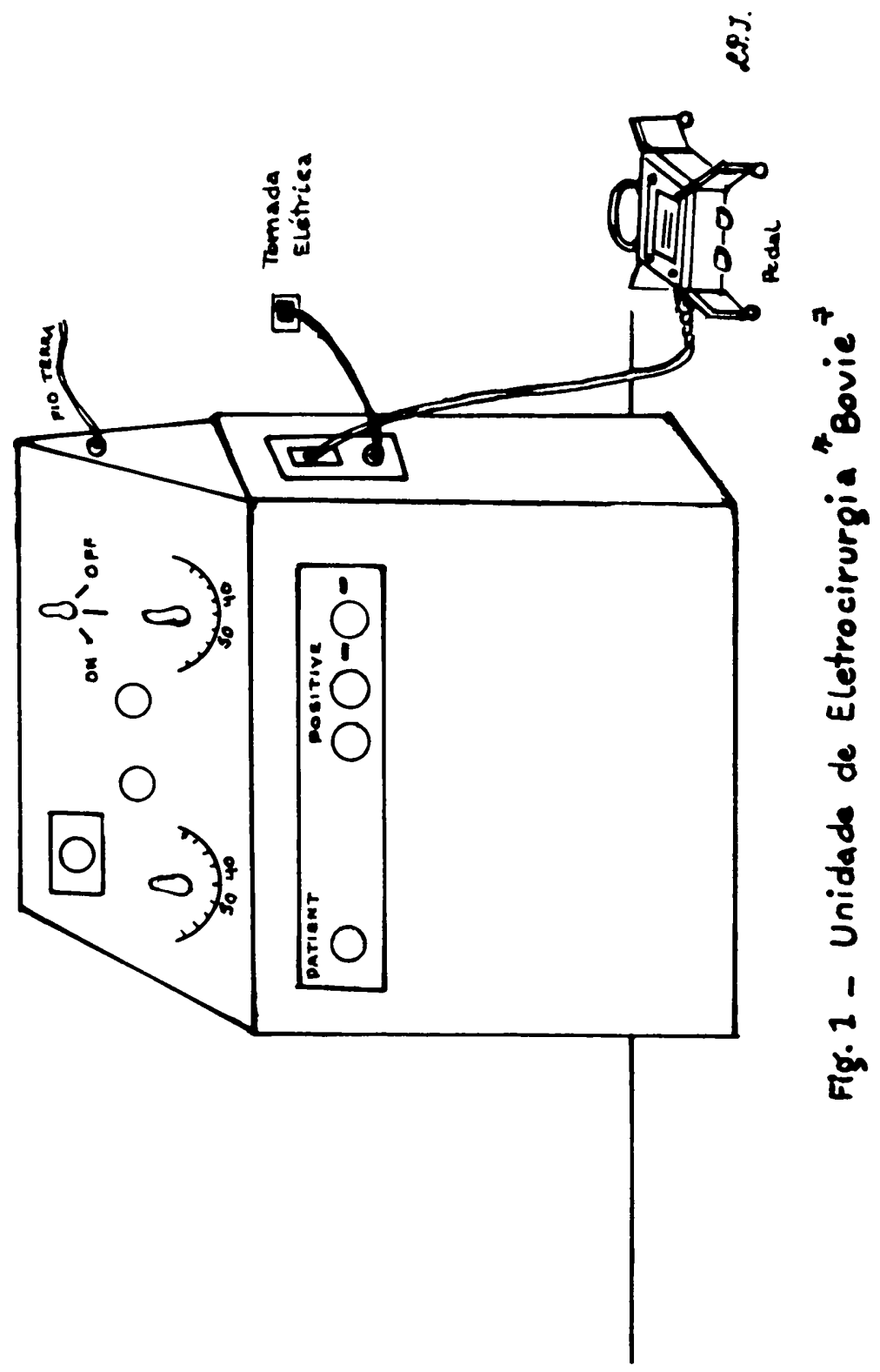


A descarga elétrica (de baixa amperagem - intensidade - e alta frequência), passando através de extremidades ponteagudas, e em contato com tecidos, produz CALOR e este será regulado pelos mecanismos do aparelho. 0 efeito físico da eletrucirurgia baseia-se fundamentalmente na $L e i$ de Joule (1), ou seja, na energia térmica produzida no organismo pela passagem da corrente elétrica. Convém salientar que os termos eletrocirurgia e eletrocauterização nem sempre são usados correta ou apropriadamente. $\mathrm{Na}$ eletrocinurgia, o calor é produzido, no tecido, pela passagem da corrente elétrica. Na eletrocauterização, o tecido é aquecido pelo calor de um metal quente e não há passagem de corrente elétrica.

$\mathrm{Na}$ eletrocirurgia, uma corrente elétrica de alta frequência aquece a ponta metálica do elétrodo positivo e passa através do corpo do paciente, que está situado entre dois elétrodos: o positivo (ponta do bisturi) e o inativo ou dispersivo (placa do paciente).

A ELETRODISSECÇÃO consiste em seccionar os tecidos com o elétrodo positivo. $O$ calor (a que nos referimos na Lei de Joule) é aplicado de modo puntiforme ou então de modo linear em casos que há necessidade de movimentar o elétrodo. A dissecação não ocorre como resultante do corte pela extremidade afiada do dispositivo: é atribuída à dissolução da estrutura molecular das células teciduais. Quando o elétrodo positivo é colocado em contato com o tecido, a potente concentração de corrente no ponto de contato resulta em suficiente calor para a desidratação das células teciduais. Uma pequena quantidade de calor gerado produz somente hiperemia do tecido; se for aumentada, produzirá evaporação da umidade da célula. A eletrodisseç̧ão ocorre, assim, pela desidratação e fusāo das células que estão próximas ao elétrodo positivo.

Para se conseguir boa cicatrização é conveniente um corte liso, com poucos coágulos e, para isto, convém que seja usada uma corrente de máxima frequência e de intensidade alta, mas não excessiva (para se evitar ação térmica desnecessária). $O$ eletrodo deve somente tocar os tecidos, sem pressão ou tração, com a ponta, para que a corrente elétrica seja a mais

(1) Lei de Joub - As correntes elétricas são reveladas por seus efeitos, entre os quais está o chamado ofeito de Joulo, que se acha relacionado com as trocas de energia que acompanham o movimento de cargas no interior do condutor e das quais resulta aumento da energia interna do mesmo. Como consequência, a tempera tura do condutor tende a aumentar, resultando, daí, transferência de calor daquele para o exterior. 
ชั

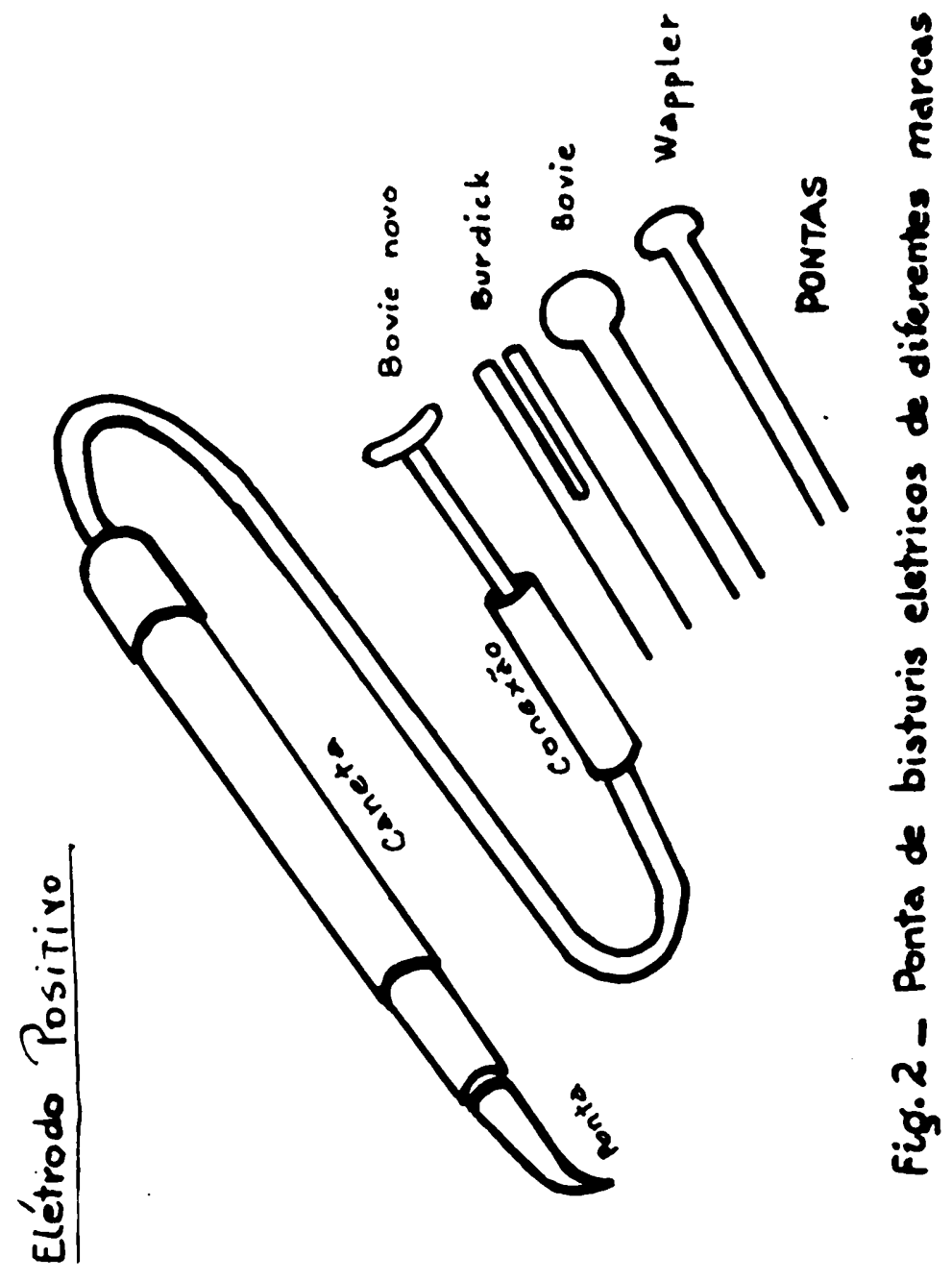




\section{Clétrodo Inatty:o}

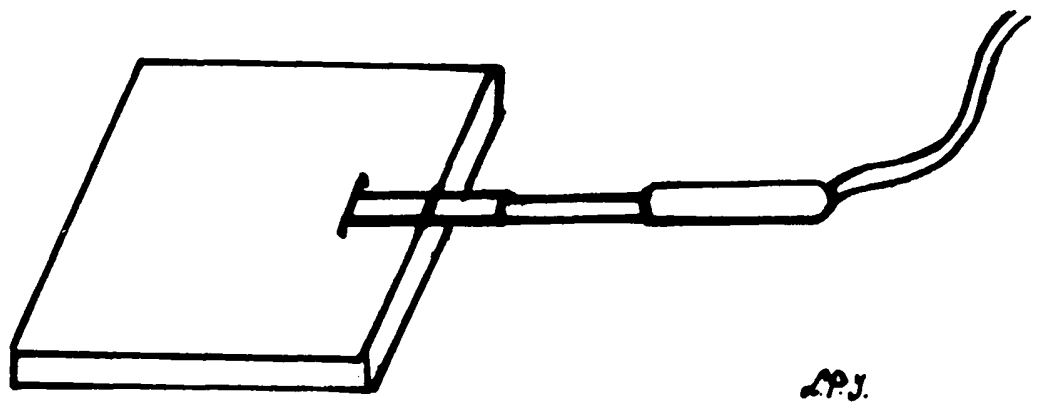

\section{Fig. 3 - Placa dispersiva}

densa (2) possivel.

Obtém-se a ELETROCOAGULAÇÃO empregando-se intensidade maior e frequência menor que a usada para a disseç̧ão. Há desidratação das células, solidificação das proteínas e retração dos tecidos. A corrente elétrica obstruirá todos os espaços sanguíneos e linfáticos, de modo que seu uso É, praticamente, sem extravasamento de líquido. É muito importante manter seco o campo operatório, pois caso contrário. desenvolver-se-á uma crosta de sangue que impedirá a coagulação profunda. A eletrocoagulação pode ser realizada por meio de:

a) aplicação direta do elétrodo ativo sobre a área desejada (método direto, mais usado para hemorragias capilares);

b) pinçamento do vaso com uma pinça hemostática, tocandoa $2 / 3$ de $\mathrm{cm}$ acima de sua ponta com o elétrodo positivo (método indireto, o mais usado);

(2) Densidade de corrente: é a quantidade (intensidade) de corrente que percorre uma unidade de superficie, ou seja, $A / \mathrm{cm}^{2}$ ( $A=$ ampère).

Equecio do continuidade: as Jensidades de corrente são inversamente proporcionais às áreas das secções retas do condutor. 
c) distância do eletrodo ativo de $2-8 \mathrm{~mm}$ do local a ser coagulado: a faísca salta esse pequeno espaço e atinge o tecido (método à distância).

\section{DEFINIÇÃO DE TERMOS}

Durante a explicação do mecanismo da eletrodissecção e da eletrocoagulação, mencionamos dois termos que julgamos importante analisar: densidade da corrente elétrica e resistência do condutor.

Distribuição da corrente

Correntes alternadas, geradas pelas unidades de eletrocinurgia, comportam-se em alguns aspectos, do mesmo modo que a eletricidade estática, isto $e$, distribuem-se sobre a superfície externa de um objeto e não dentro do mesmo. Por outro lado, concentram-se nas pontas agudas de um condutor ou, no caso de superfícies irregulares, nas saliências pontiagudas das mesmas.

Aplicação prática

Estas propriedades foram aplicadas: a) na construção e uso do bisturi elétrico: qualquer que seja o formato do bisturi, ele precisa ter uma extremidade pontiaguda, onde se concentra a corrente elétrica de alta densidade, que é responsável pelos efeitos térmicos sobre o tecido (Figs. 4 e 5); b) na construção e uso do elétrodo inativo ou placa dispersiva, sobre a qual distribue-se uma corrente de baixa densidade, com efeito térmico moderado.

O corpo do paciente fica situado entre o bisturi e a placa dispersiva. A corrente alternada passa pelo bisturi produzindo no tecido o efeito desejado e atravessa o corpo à procura da placa dispersiva, que está ligada ao fio terra pelo qual será eliminada. Se o contato entre o corpo do paciente e a placa dispersiva for regular e homogêneo, a corrente que se distr1bui pela placa será de fraca densidade e portanto eliminada sem causar dano? ao paciente. 


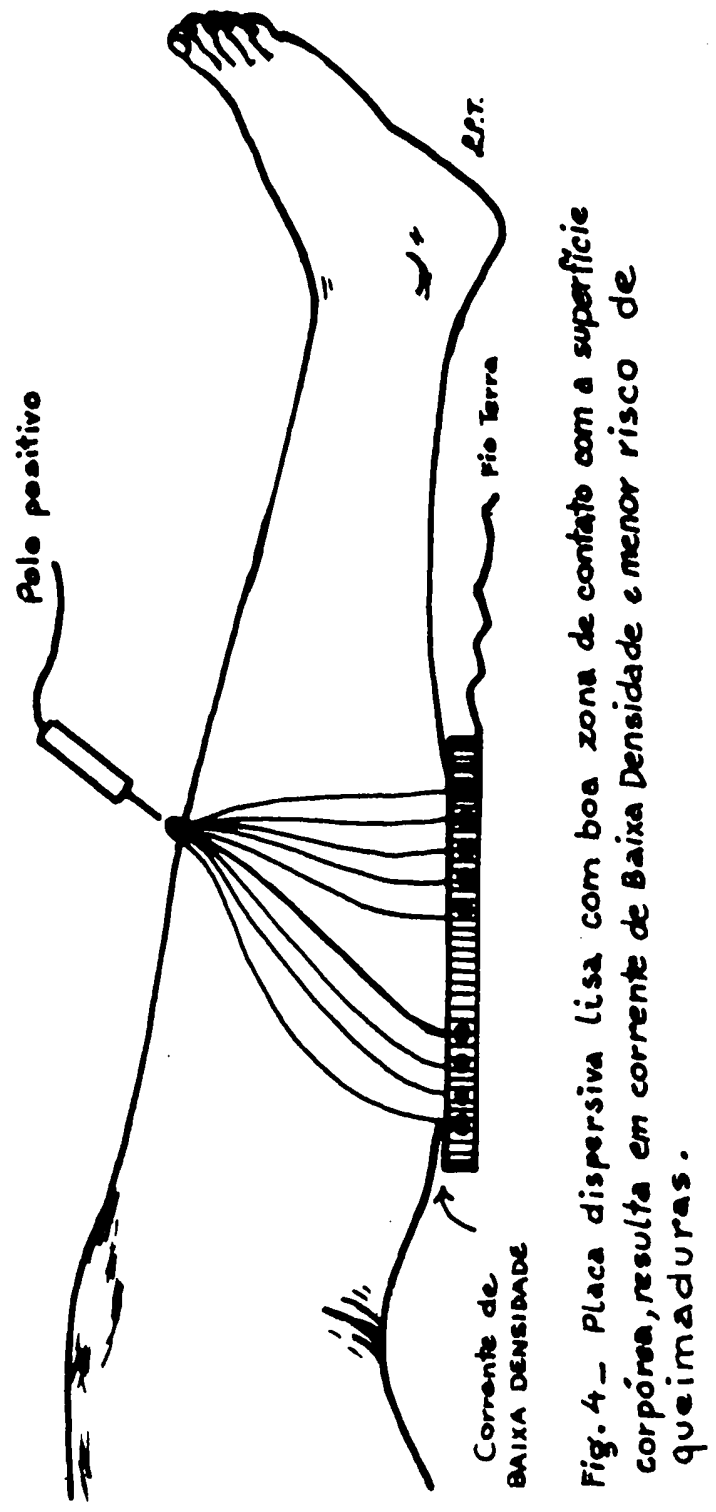




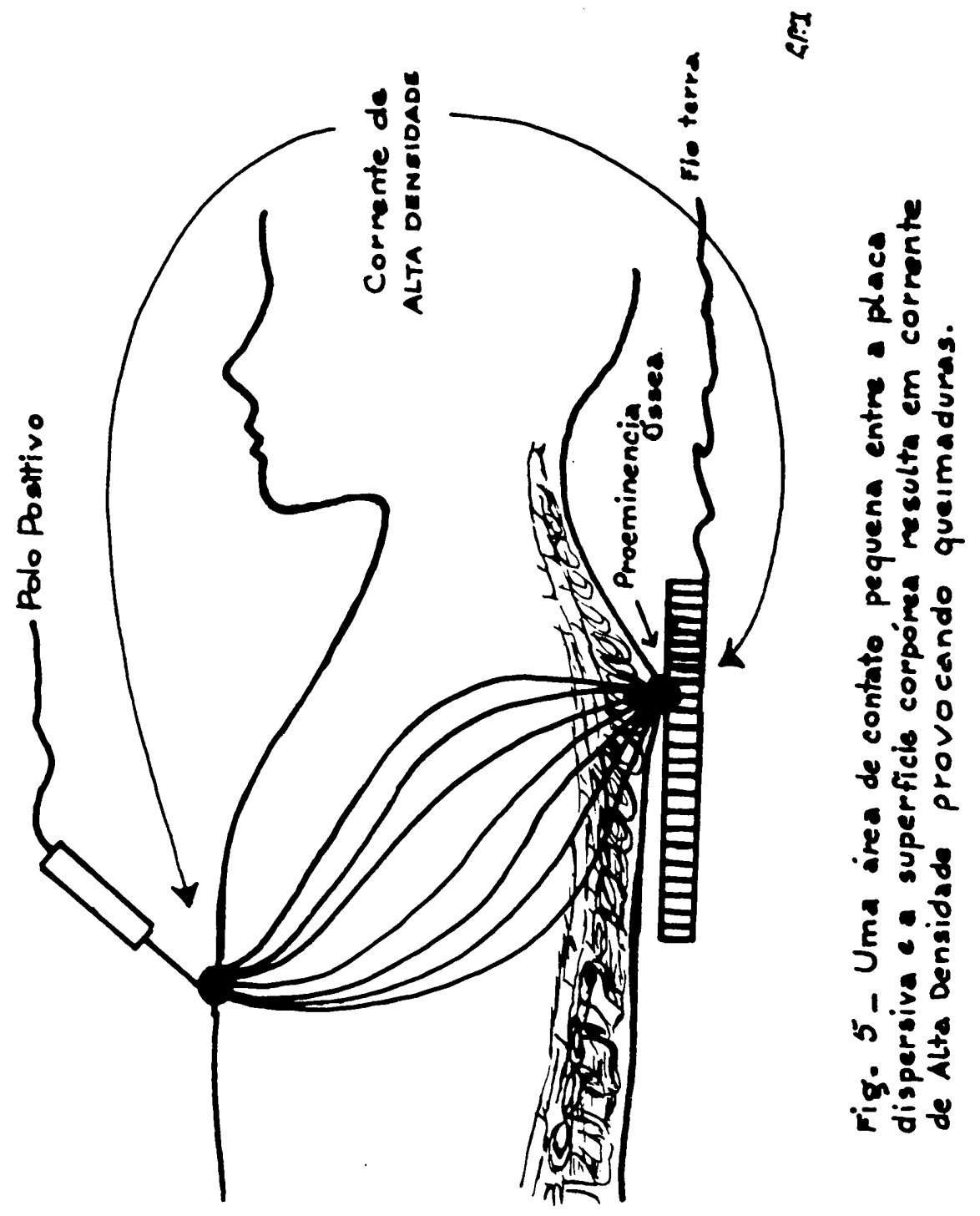


Se, entretanto, houver irregularidade na placa dispersiva (no caso de placa de chumbo ou saliência óssea) o contato do corpo do paciente com esta far-se-á apenas em alguns pontos e a corrente concentrar-se-á nessas pequenas áreas, com alta densidade, causando queimaduras nos pontos de contato.

A correção no uso, localizaçāo e conexão da placa dispersiva é um dos fatores de maior importância para a segurança do paciente. Não há tamanho ideal da placa inativa, pois, o que importa é a real dimensão da superfície em contato com o paciente. Em média, tais placas medem $20 \times 35$; geralmente são de aço inoxidável, pois, este material facilita a limpeza, resiste à corrosão eletrônica e é durável. $\mathbf{O}$ motido do seu uso é proporcionar uma passagem para a corrente de alta frequência introduzida pelo elétrodo positivo. Se a placa dispersiva não for conectada à unidade de eletrocirurgia e ao fio terra, não poderá atuar como uma passagem para a corrente elétrica de alta frequência; esta corrente se dirigirá, então a qualquer caminho possível , escolhendo o que oferecer a menor resistência; este caminho poderá ser. entre outros, uma perneira metálica, um suporte de braço metálico, uma área de contato entre o arco da mesa cirúrgica e o braço do paciente, elétrodos de ECG* e EEG*;"ou a coberta da mesa cirúrgica (principalmente quando molhada). Note-se que a corrente poderá aquecer perigosamente a tubulação condutiva do equipamento de anestesia. Se a placa dispersiva estiver apropriadamente conectada à unidade de eletrocirurgia e ao fio terra, mas oferecer pouco contato com o paciente, ocorrerá a mesma problemática, se bem que em grau menor, mas, ainda assim, prejudicial ao paciente. Contato insuficiente entre placa e paciente pode ser resultante de colocação inapropriada, de condições especiais da pele (presença de muitos pelos, tecido escarificado ou morto, pele muito seca) ou pode ocorrer quando a placa deslisa sob o paciente quando este é movimentado, mudando de posição, ou quando, inadvertidamente, coloca-se campo entre a placa e a zona de contato do paciente.

Na maioria das vezes, a placa dispersiva é colocada debaixo da pantorrilha, ou nádega. 0 importante é evitar áreas com proeminèncias ósseas (sacro, tíbia, pelvis, escápula), pois essas proeminências tornar-se-ão passagem de corrente de alta densidade (menor área de contato), ocasionando queimaduras. Alguns autores acham que a colocação da placa deve ser

- Eletrocardiograma

- Eletroencefalograma 
relativa ao local da cinurgia, a fim de que se evite que a corrente passe pelo eixo cardíaco (fator de máxima importância em pacientes com implantação de marca-passo cardíaco artificial que causa baixa do limite de resistência elétrica e, por isto, sensibilidade elétrica maior). A localização da placa dispersiva também tem influência na interferência em outros equipamentos elétricos da SO. Se a passagem da corrente pode ser tal que não inclua ou coincida com a posição de um elétrodo do monitor, a interação será grandemente diminuída. Em geral, aconselha-se a colocar a placa o mais próximo possível da área operatória e monitorizar com elétrodos o mais longe possível desta área operatória (por exemplo: em neurocirurgia, a placa deve ser colocada sob os ombros, e as conexões do monitor poderão ser do tórax para as pernas). A tendência no atual esquema, (design) de aparelhos, como parte de um sistema, é planejar equipamentos que rejeitem a interferência de correntes de alta frequència.

Resistência elétrica do condutor

Cada tipo de tecido tem uma resistência elétrica que the é característica. Por exemplo, consideramos a resistência do tecido muscular como unitária, por ser a menor em relação à dos outros tecidos; a do tecido adiposo é umas vinte vezes; a do tecido cerebral, cinco vezes e a da pele, duas vezes maior. Segundo o valor desta resistência elétrica, a coagulação ou a lesão térmica será maior ou menor. Lembrando a lei de Joule, teremos que o maior efeito calórico ocorrerá onde a resistência é maior, pois:

$$
\mathrm{U}=\mathrm{ki}^{2} \mathbf{r t}
$$

onde $\mathbf{k}$ é o coeficiente de proporcionalidade (no sistema Giorgi $\mathbf{K}=\mathbf{0 , 2 4}$ ), ou seja: a quantidade de calor $(U)$ de um condutor elétrico (o organismo. no nosso caso) é diretamente proporcional à resistência ( $(r)$ e ao quadrado da intensidade da corrente (i) e está na dependência direta do tempo durante o qual a mesma passa ( $t$ ). Duplicando-se, por exemplo, a resistência do condutor (r), duplica-se o número de calorias geradas (U). Um pequeno aumento da intensidade $(0,5$ a $1 \mathrm{~A})$ quadruplica a produção de calor.

Aconselha-se o uso de um creme condutor (por exemplo, pasta de ECG) como lubrificante da placa, com o objetivo de um contato mais 
fntimo e diminuição da resistência da pele pelo aumento da umidade local. E importante, entretanto, escolher um creme condutor que não seque durante o ato cirúrgico, pois, do contrário, o creme funcionará como isolante e não como condutor.

\section{VANTAGENS E DESVANTAGENS DA ELETROCIRURGIA}

\section{Vantagens}

- a incisão é esterilizante, com impossibilidade de propagação de germes ou células neoplásicas pelo bisturi;

- há obliteração dos capilares e interstícios linfáticos, diminuindo, assim a hemorragia capilar e a secreção pós operatória da ferida;

- a hemostasia é rápida, permitindo melhor visualização do campo cirúrgico.

Desvantagens

- ñ̃o serve para obliterar vasos medianos ou grandes;

- necrose de tecido: não se consegue evitar a combustão das células mais próximas a incisão, com o risco de haver complicaçð̃es na cicatrização.

\section{O ENFERMEIRO E A UNIDADE DE ELETROCIRURGIA}

Baseados no que acabamos de analisar, em relação ao funçionamento e objetivos da Unidade de Eletrocirurgia, deduziremos que o equipamento deve estar nas mãos de pessoal com ele familiarizado. 0 problema básico $e$ a prevenção de acidentes. Uma queimadura, grave às vezes, poderá resultar do uso de um bisturi elétrico. As causas podem ser: 
- conexão impropria entre a unidade e a placa dispersiva ou inativa;

- contato falso ou insatisfatório entre a placa dispersiva e o paciente;

- conexão imprópria entre a unidade (ou placa dispersiva) e o fio terra da SO e/ou o fio terra central do hospital;

- contato do paciente com partes metálicas da mesa cirúrica ou com acessórios.

Outro problema que não deve ser esquecido nem menospreza-

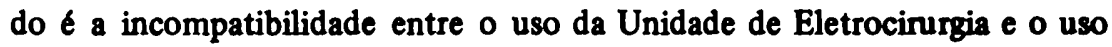
de gases anestésicos explosivos. Como o uso da unidade envolve a formação de arcos elétricos e a existência de fáscas, é lógico que se deve tomar precaução para se evitar a ignição de gases inflamáveis. Felizmente, 0 aumento do uso dé gases não explosivos está reduzindo esta problemática.

A avaliaçã่o de todas estas circunstâncias envolvendo queimaduras $e$ interferếncias necessita do aux nlio de um competente engenheiro hospitalar. Entretanto, todo o individuo responsável pelo uso do equipamento deve conhecer os aspectos básicos de seu manejo e as possíveis complicaçoes, com vistas à prevenção de acidentes (queimaduras, explosరes, choques).

Em resumo, os cuidados que devem ser observados pelo enfermeiro de SO quanto ao funcionamento do aparelho e cuidados com o paciente são dados a seguir:

- Observar as instruçðes sobre o manejo do aparelho.

- Conhecer os objetivos, funcionamento e manejo da unidade.

- Inspecionar se todo o material está em boas condiçóes, se não há partes de fio elétrico expostas, se as conexžes e tomadas elétricas estão em ordem.

- Verificar se a voltagem da corrente elétrica do interruptor 
da SO corresponde a do aparelho.

- Verificar se o comutador de entrada de corrente elétrica está em $O f f$, se as manípulas reguladoras da intensidade da corrente estão em Zero.

- Selecionar o local apropriado e colocar a placa inativa de modo a proporcionar boa área de contato, antes de a equipe cirúrgica iniciar o preparo da área operatória.

- Evitar o contato do paciente com outras partes metálicas da mesa ou de acessórios, forrando bem estes locais com campos ou coxins e revisando-os após o paciente ser colocado em posição especial para a cirurgia proposta.

- Conectar a placa dispersiva com a unidade de eletrocirurgia no local assinalado PATIENT, INACTIVE ou INDIFFERENT.

- Ao colocar o paciente em posição especial para a cirurgia, rever a colocação da placa e possível contato com outras partes metálicas. terra da SO.

- Ligar o fio terra da unidade de eletrocirurgia ao dispositivo

- Aproximar o pedal da Unidade para perto do cirurgião, se necessário, colocar uma compressa sob o pedal, para que não deslise no chão durante o uso.

- Receber do instrumentador a ponta do bisturi, ESTÉRIL, e ligá-la ao aparelho no local assinalado $A C T I V E$ ( $A T I V O)$.

- Ligar a unidade: OFF - ON, ou OFF - PAUSE - ON, nos aparelhos que necessitem de uma pequena pausa (alguns segundos) para aquecer o dispositivo.

- Evitar o umedecimento da placa inativa e de campos cirúrgicos por agentes antisséticos, que poderão tornar-se condutores de eletricidide. 
- Manter a intensidade da coagulação e da dissecção entre 40-50; estar atento às solicitação de aumento ou diminuição de intensidade.

- Observar continuadamente o funcionamento do aparelho e qualquer reação anômala no paciente ou na equipe: os sistemas de alarma (luz vermelha, campainha) denunciam internup̧̧ðes de conexões do aparelho que deverão ser revistas e ajustadas. Uma possibilidade que deve ser lembrada é a de que a lâmpada do alarma possa ter queimado. Neste caso, pode haver uma falha nas conexões e o alarma não funcionar. Recomenda-se, por isto, optar pelas Unidades que tenham um foco luminoso que acende quando o aparelho está em ordem e apaga (ou outra luz se acende) quando há qualquer problema. A grande falha destes sistemas todos é que não denunciam casos de inadequados contatos entre o paciente e a placa dispersiva, podendo este fato, então, passar despercebido e causar uma queimadura no paciente.

- Lembrar que, apesar do excesso de eletricidade ser descarregado pelo fio terra, correntes de pequena amplitude podem se propagar através do material isolante ou das peças. Normalmente, todo o equipamento de corrente alternada tem uma descarga de 60 Hertz (média de oscilações/ seg.). Os seus efeitos fisiológicos dependerão da resitência do paciente e da voltagem aplicada. Quando o indivíduo está em contato com uma variedade de fontes de eletricidade (equipamentos eletrônicos diferentes aplicados a um mesmo paciente), quantidades significativas de corrente podem circular atraves dele e causar severos efeitos.

- Estar alerta a interferências com outros equipamentos elétricos conectados e em uso simultâneo no mesmo paciente. Isto se deve a baixa corrente de $60 \mathrm{Hertz}$ que circula continuadamente entre o circuito e não a alta frequència da corrente.

Lembrar-se de verificar o isolamento, pelo fio terra, de qualquer aparelho-monitor adaptado ao paciente. $O$ isolamento de todos os aparelhos e da unidade de eletrocirugia deve ser feito no mesmo fio terra da SO, para se evitar o desenvolvimento de diferenças de potenciais entre 0 paciente e as várias peças do equipamento, quando houver falha de qualquer componente.

- Lembrar-se da incompatibilidade do bisturi elétrico com o uso de gases anestésicos explosivos (éter. ciclopropano). 
- Terminada a cirurgia, desligar o aparelho, sem puxar os fios, e retirar os acessórios. Guardá-los adequadamente em seu devido lugar.

- Após o uso, limpar o dispositivo do eletrodo positivo (caneta, ponta e fios) com álcool ou benzina, e esterilizá-lo na estufa em vapor de formalina $\left(500^{\circ} \mathrm{C}, 2\right.$ horas, $5 \%$ ).

- Limpar e guardar com o aparelho, o pedal, a placa e os

fios.

- Elaborar um plano de controle periódico para todas as pecas do equipamento, com o auxfllio do responsável pela segurança elétrica do hospital. Lembrar-se da inconveniência de misturar peças de marcas diferen, tes. A maioria das companhias desenham suas próprias peças, para maior segurança. Os hospitais não compram com exclusividade, de um só fabricante e, se os equipamentos forem misturados, a segurança será sacrificada. 0 ideal é ter uma pessoa qualificada para testar o funcionamento e o estado de manutenção, para saber o que fazer em caso da falha e reconhecer defeitos em potencial.

- Desenvolver, com o auxflio de pessoal especializado, programas de atualização e educação em serviço para os funcionários da SO, sobre o uso, manejo e manutenção da Unidade de Eletrocirurgia (bem como de todos os demais aparelhos usados na SO).

Note-se que não só o equipamento em si necessita ser testado regularmente, como o ambiente hospitalar deve ser seguro. Isto exige uma rotina de manutenção: controle de tomadas, interruptores, isolamento da SO pelo fio terra, etc.. Qualquer anormalidade com tomadas ou acessórios elétricos deve ser imediatamente comunicada ao responsável pela segurança elétrica.

CASTELlaNOS, B.P. - Patient's sofety in the operating roon. The nurse and the electrosurgical unit. Rev. Esc. Enf. U.S.P. 7(2): 123-139, 1973.

The electrosurgical unit is an electronical equipment that promots electrocoagulation and electrosurgery. As any other electronical equipment, its potential benefits can be annulated or its effects can be 
tragically disastrcus to the patient, if there are omissions or misuse in its handling and maintenance. The analysis of the hazards involving burn injuries and interference problems with patients already monitorized contribute to the safety of the patient in the operating room. Possible cause of burn injuries are analysed and the role of the nurse emphasized.

\section{BIBLIOGRAFIA}

ALVIM, M.F. - A enfermagem na eletrocirurgia. Rev. Paul. Hosp., 15 (12): 46-49, 1967.

BATTING, C.G. - Electrosurgical burn injuries and their prevention. JAMA, 204 (12): 91-5, 1968.

BILLING, G.A. - Patient safety and electrosurgery. AORNJ, 14 (8): 62-68, 1971.

FOSWELL, L.G. - Equipment and personnel controls can improve safety and reduce insurance costs. Mod. Hosp., 118 (5): 109-112, 1972.

GINSBERG, F. - A manual of operating room technology. 5th ed. Phila delphia, Lippincott, 1966, p. 183.

HOW a safety program works. Mod.Hosp., 118 (5): 99, 1972.

KEENE, J. - Cooperative program in California teaches electrical safety to staffs. Mod. Hosp., 118 (5): 103-106, 1972.

KERSCHNER, M. - Tratado de técnica operatória general y especial, 3a ed. Barcelona. Ed. Labor, 1965. Tomo I, 19 parte, p. 122.

OR PANEL - Hazards from electrical equipment. Hosp. Topics, 48 (7): 93-100, 1970.

PROPER electrical equipment maintenance requires proper facilities and staffs. Mod. Hosp., 118 (5): 106-107, 1972.

RODRIGUES, E.C. \& PIERONI, R.R. - Física. 3a ed. São Paulo, ClássicoCientifica, 1956, V. 3, p. 315.

SALZANO, S. - Estudo da ação do paraformico nas bactérias em forma esporulada. Rev. Esc. Enf. da USP, 2 (2): 46-57, 1968.

TRAINING and testing can help ensure electrical safety. Mod. Hosp., 118 (5): 97-99, 1972. 